\title{
Measurement of Stopping Power, Residual Range and Equivalent Dose Rate of $\alpha$ - Particles in Polymers PP and PE
}

Ahmed K. Mheemeed

Laith R. Mohammed

Ali KH. Hussain

Department of Physics / College of Education

University of Mosul

Received

$10 / 03 / 2008$
Accepted

03 / 06 / 2008

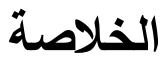

V.79 MeV تم في هذا البحث قياس قدرة الإيقاف لجسيمات ألفا ذات الطاقة الابتدائية

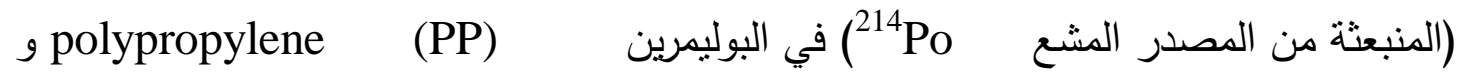
polyethylene (PE) النظرية باستخدام برنامج

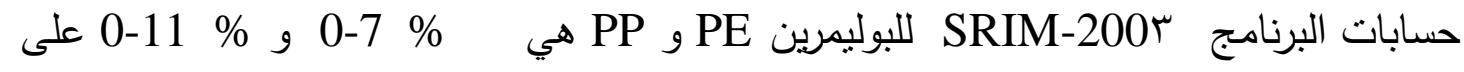
التوالي. وضعت معادلات تجريبية تربط بين قدرة الإيقاف والطاقة لكل من البوليمرين أعلاه. كما تم حساب الطاقة المتبقية والمدى المتبقي ومعدل الجرعة المكافئة.

\footnotetext{
Abstract

The stopping power of $\alpha$-particles of initial energy 7.69 MeV (emitted from ${ }^{214} \mathrm{Po}$ source) have been measured in the polyethylene(PE) and polypropylene(PP) using surface barrier detector technique and compared with calculated value by SRIM-2003 program. The deviations of the measured data from SRIM's results in PE and PP films are approximately about $0-7 \%$ and $0-11 \%$. An empirical formulae between the stopping power and energy have been found. The residual energy, the residual range and the equivalent dose rate also calculated.
} 


\section{Introduction}

Knowledge of the stopping power, energy loss, range, straggling and equivalent dose rate of ions in air, tissue and polymers are very important in many research and application fields, such as radiation dosimetry, radiation biology (such as cell lethality, cytogenesis changes, mutagenesis and DNA recombination), radiation chemistry, radiotherapy and nuclear physics [1-5]. Different methods have been reported for measuring the stopping power of charged particles such as direct energy loss measurement through films, backscattering from thick substrate covered with deposited absorbing layers, gamma resonance shift measurements, self-supporting method and an indirect verification of the stopping power based on alpha energy losses in air [2-7].

Many experimental and theoretical studies about energy loss, stopping power, range, straggling of ions such as $(\mathrm{H}, \mathrm{He}, \mathrm{Li}, \mathrm{C}, \mathrm{O})$ and equivalent dose have been carried in many different kind of polymers such as polypropylene, polyethylene and polycarbonate [8-13] specially polyethylene since its molecular structure is very close to body equivalent materials [14].

The present work is concerned about the information of the stopping power of alpha particles of initial energy $7.69 \mathrm{MeV}$ (emitted from ${ }^{214} \mathrm{Po}$ source) in polyethylene with low density (PE) and polypropylene (PP) by using surface barrier detector. The residual energy, residual range and equivalent dose rate have been calculated. The measured values of the stopping powers have been compared with the corresponding computed values based on Ziegler et al (SRIM-2003) [15].

\section{Theoretical part}

Stopping power of a medium can be defined as the average unit of energy loss suffered by the charge particles per unit path length in the medium under consideration. $[16,17]$

Stopping power consists of two components: collisions and radiative. The first is the most important for $\alpha$-particles, resulting from the collision interaction between the incident particles and atomic electrons. Mass collision stopping power is widely used to reduce the dependence on the medium density $(\rho)$ [16]. The total stopping power can be obtained from SRIM-2003 program [15], which calculates the stopping power and range of ions $(10 \mathrm{eV}-2 \mathrm{GeV} / \mathrm{amu})$ in matter using a quantum mechanical treatment of ion-atom collision (the manual of SRIM refers to the moving atom as an "ion", and all target atoms as "atom"). A full description of the calculation was given by Ziegler and Biersack [15]. 
Maximum range $\left(\mathrm{R}_{\max }\right)$ of $\alpha$-particles is defined as the maximum penetration depth of the particles beam in to the target $[13,16]$. Residual range $\left(R_{\text {res }}\right)$ has been calculated from the relation [4]:

$\mathrm{R}_{\mathrm{res}}=\mathrm{R}_{\max }-\Delta \mathrm{x}$

Where $R_{\max }$ is the maximum range of $\alpha$-particles of $7.69 \mathrm{MeV}$.

$\Delta \mathrm{x}$ is the target thickness.

The absorber dose rate $\check{D}$ of $\alpha$-particles in a given material is given by [16].

$\check{\mathrm{D}}(\mathrm{Gy} / \mathrm{sec})=\varphi \times 1.602 \times 10^{-10} \times(\mathrm{dT} / \rho \mathrm{dx})$

Where $d T / \rho d x$ is the stopping power for $\alpha$-particles.

$\Phi$ is the $\alpha$-particle fluence.

Consider a chain of decays: $1 \rightarrow 2 \rightarrow 3 \rightarrow \ldots$. With decay constant $\lambda_{1}, \lambda_{2}, \lambda_{3}, \ldots$ etc .If the parent is relatively long lived $\left(\lambda_{1}<<\lambda_{2}\right)$, then a secular equilibrium is obtained [18].

$\lambda_{1} \mathrm{~N}_{1}=\lambda_{2} \mathrm{~N}_{2}=\ldots \ldots . .=\lambda_{\mathrm{n}} \mathrm{N}_{\mathrm{n}}$

The parent nucleus ${ }^{226} \mathrm{Ra}\left(\mathrm{t}_{1 / 2}=1600\right.$ years $)$ decay to ${ }^{222} \mathrm{Rn}\left(\mathrm{t}_{1 / 2}=3.8\right.$ day $)$ $\ldots .{ }^{214} \mathrm{po}\left(\mathrm{t}_{1 / 2}=164 \mu \mathrm{s}\right)$..

then

$$
\lambda\left({ }^{226} \mathrm{Ra}\right)<<\lambda\left({ }^{214} \mathrm{po}\right)
$$

where $\mathrm{S}$ is the activity $=\lambda \mathrm{N}$

$$
\mathrm{S}\left({ }^{226} \mathrm{Ra}\right)=\mathrm{S}\left({ }^{214} \mathrm{po}\right)=2 \mu \mathrm{ci}
$$

$\varphi=(\mathrm{SG} / \mathrm{A})$

where $\mathrm{A}$ - is the area of the polymer.

G- is the geometry factor which is calculated from [19].

$\mathrm{G}=\left[1-\mathrm{d} /\left(\mathrm{d}^{2}+\mathrm{r}^{2}\right)^{1 / 2}\right] / 2$

Where $\mathrm{d}$ is the distance between the polymer and the source $=0$

then $\mathrm{G}=1 / 2$

then $\varphi=\left(2 \times 3.7 \times 10^{4} \times(1 / 2)\right) / \pi(0.5)^{2}$

$$
\varphi=4.7 \times 10^{4} \alpha / \mathrm{cm}^{2} . \mathrm{sec}
$$

Equivalent dos rate $\hat{\mathrm{H}}(\mathrm{Sv} / \mathrm{sec})$ has been calculated from the equation [16].

$\hat{\mathrm{H}}(\mathrm{Sv} / \mathrm{sec})=\check{\mathrm{D}}(\mathrm{Gy} / \mathrm{sec}) \times \mathrm{Q}$

Where $\mathrm{Q}$ is the quality factor $=10[16]$.

$\hat{\mathrm{H}}(\mathrm{Sv} / \mathrm{hr})=0.2718 \mathrm{x}(\mathrm{dT} / \rho \mathrm{dx})$ 


\section{Experimental part}

\section{1 films preparation and thickness measurement.}

To prepare a thin film of polymers (PE and PP), we used the following procedure, a certain amount of polymers was dissolved in a Xylene solvent at a temperature from 85 to $100{ }^{\circ} \mathrm{C}$, using a magnetic stirrer. Then the hot mixed solution is poured in a horizontal vessel of inner diameter $5 \mathrm{~cm}$ and allowed to cool to room temperature. For more details see previous work [3]. The thickness of the prepared films were measured from I.R. spectrum using the following relation $[2,3,20]$.

$\Delta \mathrm{x}=\mathrm{c} \operatorname{Ln}\left(\mathrm{Io}_{\mathrm{o}} / \mathrm{I}\right)$

Where $I_{0}$ is the intensity of the incident IR radiation.

I is the intensity of the transmitted IR radiation.

$\mathrm{c}$ is the absorptivity of the IR radiation by polymers and can be determined experimentally using a film of known thickness $(\Delta x)$ which determined either by weight per unit area $[3,4]$ or by using the $\alpha$-energy loss method $[13,16]$ :

$\Delta \mathrm{x}=\Delta \mathrm{E} / \mathrm{S} . \mathrm{P}$

Where S.P is the stopping power obtained from (SRIM-2003) program. $\Delta \mathrm{E}$ is the energy loss in polymers.

\subsection{Energy loss, range and equivalent dose rate .}

Energy loss $(\Delta \mathrm{E})$ measurement in polymer films have been carried out using $\alpha$-spectroscopy system as shown in Figure (1) which consists of silicon surface barrier detector (Canberra PD-50-18-100) with an energy resolution $\leq 18 \mathrm{keV}$, vacuum chamber under pressure of $10^{-2}$ torr during the experimental run, $\alpha$-particles source $\left({ }^{214} \mathrm{po}\right)^{*}$ of $7.69 \mathrm{MeV}$, preamplifier, SPECTECH-UCS-20, pulser and computer (PC). The calibration of $\alpha$-particles spectrometer was carried out using $\alpha$-particles with different energy $\left(5.48 \mathrm{MeV}, 7.69 \mathrm{MeV}\right.$ from ${ }^{241} \mathrm{Am}$ and ${ }^{214}$ po sources respectively and pulser to calculate zero alpha energy). Calibration feature makes it possible for the marker to read directly the energy. Film of known thickness was placed between $\alpha$-source $\left({ }^{214} \mathrm{po}\right)$ and the detector, peak position for the highest energy of $\alpha$-particles transmitted through the film was determined accurately by using the marker. The energy loss $\Delta \mathrm{E}$ can be obtained from the shift of the peak position from its position when there was no film between the source and the detector. This was repeated for different film thickness

- the daughter nucleus $\left({ }^{214} \mathrm{po}\right)$ is obtained from the decay of the parent nucleus $\left({ }^{226} \mathrm{Ra}\right)$. 


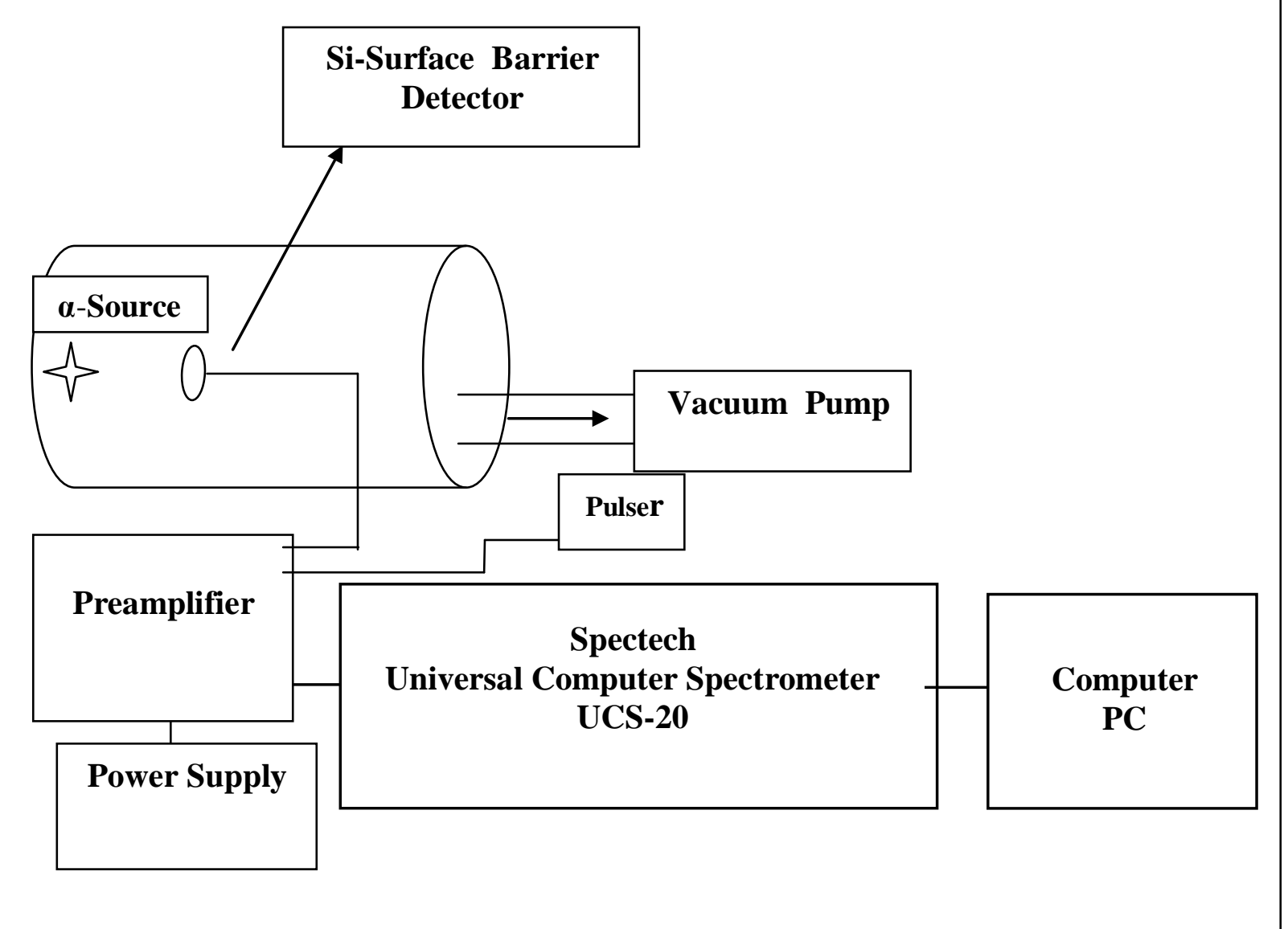

Figure(1): shows $\alpha$-spectroscopy system

The residual energy $\left(E_{\text {res }}\right)$ has been calculated from the relation[16]

$\mathrm{E}_{\mathrm{res}}=\mathrm{E}_{\mathrm{o}}-\Delta \mathrm{E}$

Where Eo is the initial energy of $\alpha$-particles $(7.69 \mathrm{MeV})$

The maximum rang $\left(R_{\max }\right)$ has been found previously from [17] which was equal $6.95 \mathrm{mg} / \mathrm{cm}^{2}$ for PP and $6.7 \mathrm{mg} / \mathrm{cm}^{2}$ for PE.

The residual range $\left(R_{\text {res }}\right)$ and the equivalent dose rate $(\hat{H})$ have been calculated from the relation (1) and (7) respectively.

\section{Results and discussion}

The stopping power (S.P) of $\alpha$-particles as a function of average energy (3.5 MeV and 7.6 MeV) are shown in Figures (2) and (3) for PE and PP respectively where the data of Rabih [20] for $(\overline{\mathrm{E}}<5.3 \mathrm{MeV})$ are added with the present measurement, which are listed in Tables (1),(2).

The alpha source employed in the previous study [20] was ${ }^{241} \mathrm{Am}$ $\left(E_{o}=5.486 \mathrm{MeV}\right)$. The average energy for $\alpha$-particles $\bar{E}=E_{o}-\Delta E / 2$. 
The above experimental data have been used to find a simple empirical equation for (S.P) of $\alpha$-particles for PE and PP respectively, as shown below:

S.P $=-701.24 \operatorname{Ln}(\overline{\mathrm{E}})+2151$

$\mathrm{S} . \mathrm{P}=17.795 \overline{\mathrm{E}}^{2}-304.79 \overline{\mathrm{E}}+2026.5$

The thickness $(\Delta \mathrm{x})$, energy loss $(\Delta \mathrm{E})$, average energy $(\overline{\mathrm{E}})$, experimental stopping power $\left(\mathrm{S}_{\mathrm{exp}}\right)$, theoretical $\left(\mathrm{S}_{\mathrm{th}}\right)$ and fitted $\left(\mathrm{S}_{\mathrm{fit}}\right)$ values for PE and PP are listed in Tables (1),(2).

Table(1): thickness, energy loss, average energy, theoretical, fitted function and experimental stopping power for $\mathbf{P E}$

\begin{tabular}{|c|c|c|c|c|c|}
\hline$\Delta \mathrm{x}\left(\mathrm{mg} / \mathrm{cm}^{2}\right)$ & $\Delta \mathrm{E}(\mathrm{MeV})$ & $\overline{\mathrm{E}}(\mathrm{MeV})$ & $\mathrm{S}_{\text {exp }}\left(\mathrm{Mev} \cdot \mathrm{cm}^{2} / \mathrm{g}\right)$ & $\mathrm{S}_{\mathrm{th}}\left(\mathrm{Mev} \cdot \mathrm{cm}^{2} / \mathrm{g}\right)^{*}$ & $\mathrm{~S}_{\mathrm{fit}}\left(\mathrm{Mev} \cdot \mathrm{cm}^{2} / \mathrm{g}\right)^{*}$ \\
\hline 0.5098 & 0.36 & $\mathrm{~V} .01$ & 706 & $750(6)$ & $737(4)$ \\
\hline 1.3878 & 1.08 & 7.15 & 778 & $778(0)$ & $772(<-1)$ \\
\hline 1.8105 & 1.418 & 6.981 & 783 & $792(1)$ & $788(<1)$ \\
\hline 3.4550 & 3.114 & 6.133 & 901 & $874(-3)$ & $879(-2)$ \\
\hline 3.8741 & 3.537 & 5.922 & 913 & $892(-2)$ & $904(-1)$ \\
\hline 0.5425 & 0.536 & 5.218 & 987 & $987(0)$ & $993(<1)$ \\
\hline 1.5355 & 1.666 & 4.653 & 1085 & $1073(-1)$ & $1073(1)$ \\
\hline 2.1675 & 2.536 & 4.218 & 1170 & $1151(-2)$ & $1142(2)$ \\
\hline 2.7868 & 3.386 & 3.793 & 1215 & $1238(2)$ & $1216(<1)$ \\
\hline 3.1870 & 3.936 & 3.516 & 1235 & $1304(7)$ & $1269(3)$ \\
\hline
\end{tabular}

- $\quad$ Percentage differences with respect to the measured values are given in parentheses

Table(2): thickness, energy loss, average energy, theoretical, fitted function and experimental stopping power for $\mathbf{P P}$

\begin{tabular}{|c|c|c|c|c|c|}
\hline$\Delta \mathrm{x}\left(\mathrm{mg} / \mathrm{cm}^{2}\right)$ & $\Delta \mathrm{E}(\mathrm{MeV})$ & $\overline{\mathrm{E}}(\mathrm{MeV})$ & $\mathrm{S}_{\text {exp }}\left({\left.\mathrm{Mev} . \mathrm{cm}^{2} / \mathrm{g}\right)}\right.$ & $\mathrm{S}_{\mathrm{th}}\left(\mathrm{Mev} \cdot \mathrm{cm}^{2} / \mathrm{g}\right)^{*}$ & $\mathrm{~S}_{\text {fit }}\left(\mathrm{Mev} \cdot \mathrm{cm}^{2} / \mathrm{g}\right)^{*}$ \\
\hline 0.2162 & 0.161 & 7.6095 & 745 & $742(<-1)$ & $738(-1)$ \\
\hline 0.3219 & 0.24 & 7.57 & 746 & $745(0)$ & $739(-1)$ \\
\hline 0.7491 & 0.572 & 7.404 & 764 & $758(<-1)$ & $745(-3)$ \\
\hline 1.4644 & 1.089 & 7.1455 & 744 & $778(5)$ & $757(2)$ \\
\hline 1.8053 & 1.287 & 7.0465 & 713 & $786(10)$ & $762(7)$ \\
\hline 2.1272 & 1.705 & 6.8375 & 802 & $805(<1)$ & $774(-3)$ \\
\hline 0.778 & 0.716 & 5.128 & 920 & $999(9)$ & $931(1)$ \\
\hline 1.4417 & 1.436 & 4.768 & 996 & $1054(6)$ & $978(2)$ \\
\hline 1.898 & 1.936 & 4.518 & 1020 & $1095(7)$ & $1013(<1)$ \\
\hline 2.839 & 3.136 & 3.918 & 1105 & $1211(10)$ & $1105(<1)$ \\
\hline 3.186 & 3.616 & 3.678 & 1135 & $1265(11)$ & $1179(4)$ \\
\hline
\end{tabular}

- Percentage differences with respect to the measured values are given in parentheses 


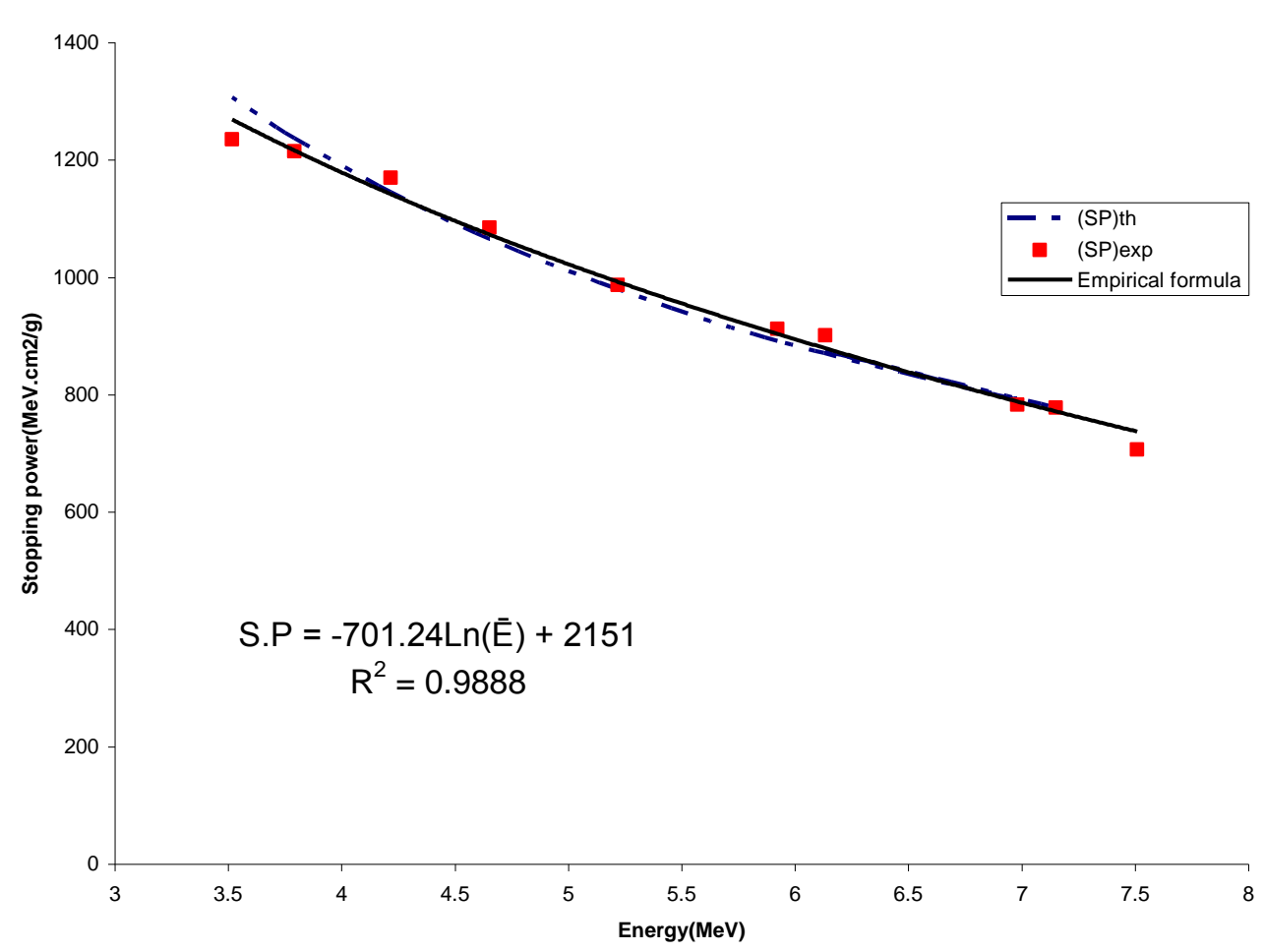

Figure(2): The relation between stopping power and average energy for PE

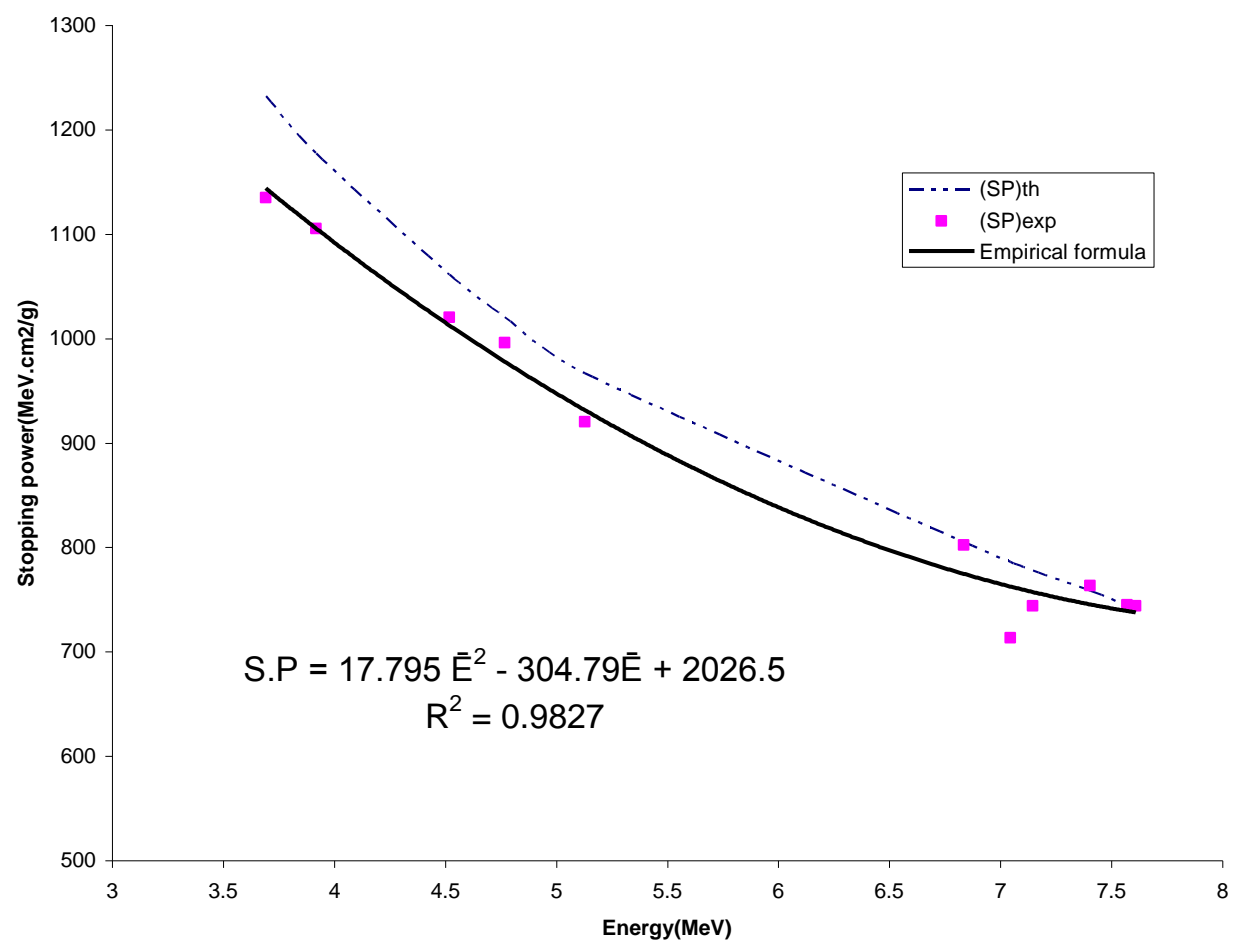

Figure(3): The relation between stopping power and average energy for PP 
The present results are compared with stopping power calculated from SRIM program and there is a good agreement between measured and calculated data .The deviations of the measured data from SRIM's results in PE and PP films are approximately about $0-7 \%$ and $0-11 \%$. On comparison between the experimental results and those yielded from the empirical formula, the percentage differences with respect to the measured values are up to $4 \%$ for PE and up to $7 \%$ for PP. One could see from the present data that the stopping power is higher in PE than in the PP. This is explained due to the higher (Z/A) value of PE as compared with PP [20].

Figures (4) and (5) shows the relation between the residual range $\left(\mathrm{R}_{\text {res }}\right)$ and residual energy $\left(\mathrm{E}_{\text {res }}\right)$ which calculated from equations (1) and (10) for PE and PP. In Tables (3),(4) we present results obtained for the residual range and residual energy for various thickness. The present experimental data have been used to evaluated a simple empirical equation as shown below:

$$
\begin{array}{ll}
\mathrm{R}_{\text {res }}=0.0686\left(\mathrm{E}_{\text {res }}\right)^{2}+0.2595\left(\mathrm{E}_{\text {res }}\right)+0.587 & \text { for PE } \\
\mathrm{R}_{\text {res }}=0.1974\left(\mathrm{E}_{\text {res }}\right)^{2}-1.3933\left(\mathrm{E}_{\text {res }}\right)+6.0583 & \text { for PP }
\end{array}
$$

The measured results are in good agreement with those yielded using the empirical formula in PE and PP.

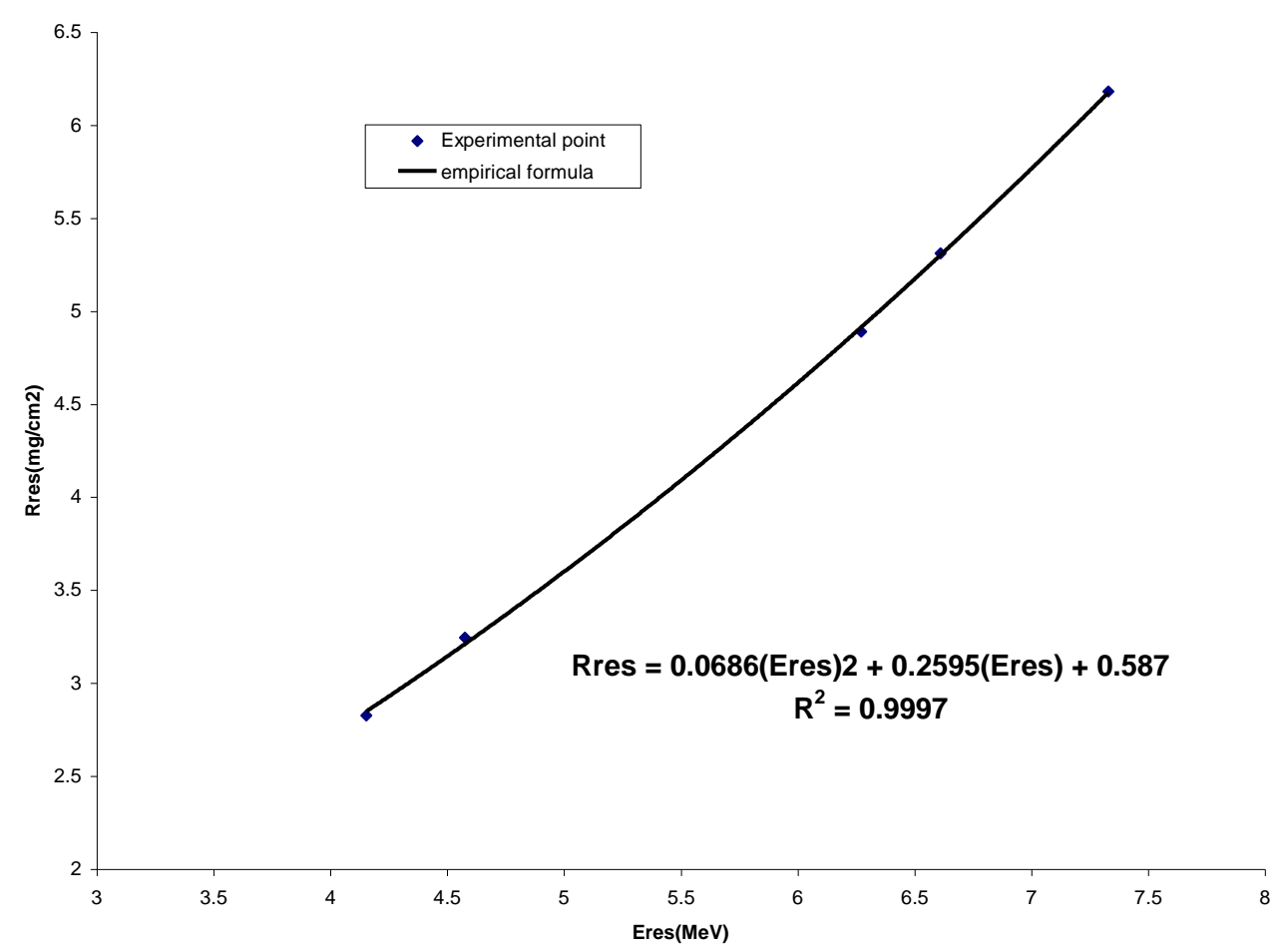

Figure (4): The residual range as a function of residual energy for PE 


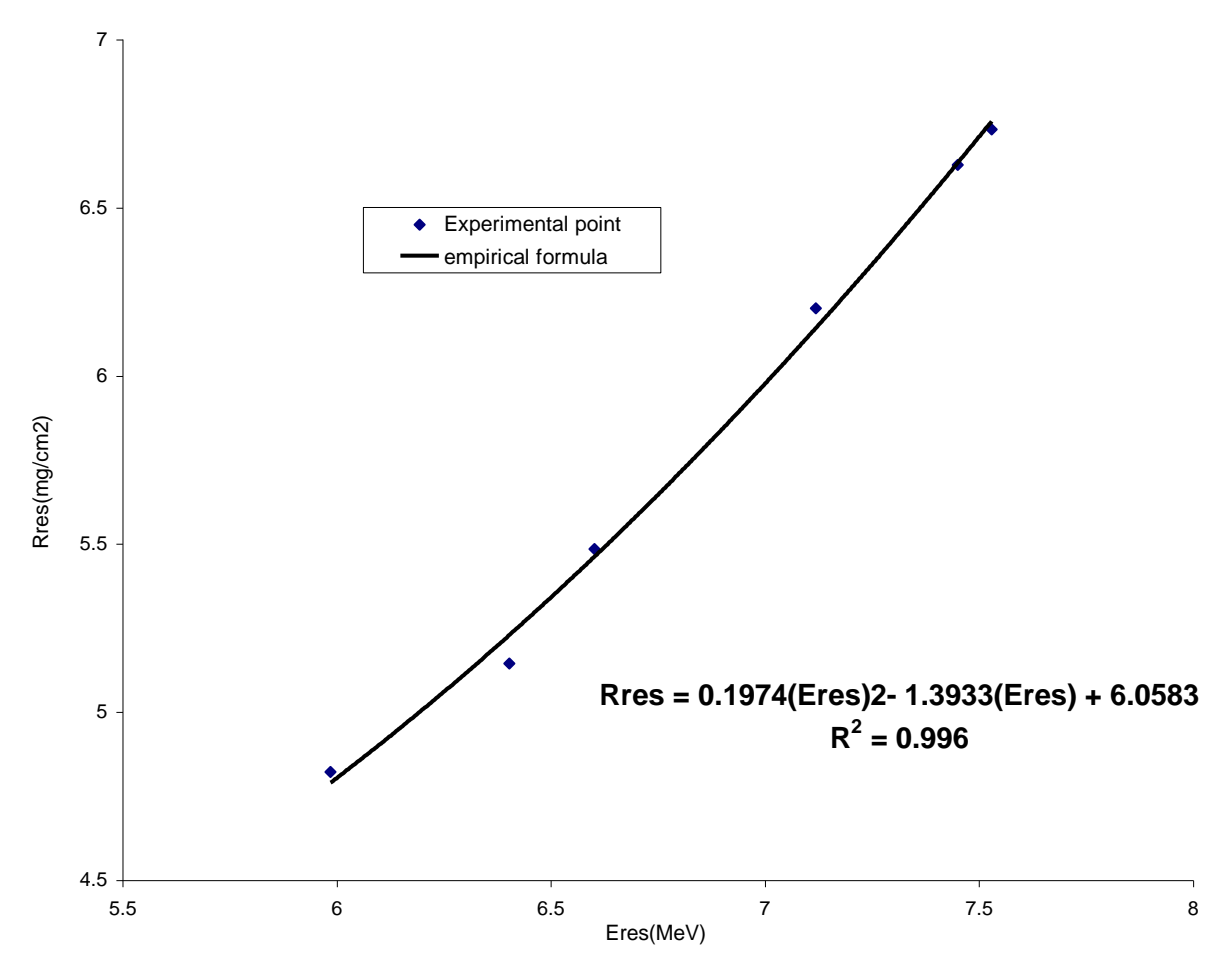

Figure (5): The relation between residual range and residual energy for PP

Table (3): thickness, residual energy and residual range for PE

\begin{tabular}{|c|c|c|}
\hline$\Delta \mathrm{x}\left(\mathrm{mg} / \mathrm{cm}^{2}\right)$ & $\mathrm{E}_{\mathrm{res}}(\mathrm{MeV})$ & $\mathrm{R}_{\mathrm{res}}\left(\mathrm{mg} / \mathrm{cm}^{2}\right)$ \\
\hline 0.5098 & 7.33 & 6.191 \\
\hline 1.3878 & 6.61 & 5.312 \\
\hline 1.8105 & 6.272 & 4.889 \\
\hline 3.4550 & 4.576 & 3.245 \\
\hline 3.8741 & 4.153 & 2.826 \\
\hline
\end{tabular}

Table (4): thickness, residual energy and residual range for PP

\begin{tabular}{|c|c|c|}
\hline$\Delta \mathrm{x}\left(\mathrm{mg} / \mathrm{cm}^{2}\right)$ & $\mathrm{E}_{\text {res }}(\mathrm{MeV})$ & $\mathrm{R}_{\text {res }}\left(\mathrm{mg} / \mathrm{cm}^{2}\right)$ \\
\hline 0.2162 & 7.529 & 6.734 \\
\hline 0.3219 & 7.45 & 6.628 \\
\hline 0.7491 & 7.118 & 6.201 \\
\hline 1.4644 & 6.601 & 5.486 \\
\hline 1.8053 & 6.403 & 5.145 \\
\hline 2.1272 & 5.985 & 4.823 \\
\hline
\end{tabular}

Figures (6) and (7), Table (5) and (6) shows the relation between the equivalent dose rate $(\hat{\mathrm{H}})$ and the thickness $(\Delta \mathrm{x})$ for PE and PP. It is interesting to note from these figures that the equivalent dose rate increases almost linearly with the thickness of PE and PP. 
Measurement of Stopping Power, Residual Range and Equivalent Dose ...

Table (5): thickness, equivalent dose rate and energy loss for PE

\begin{tabular}{|c|c|c|}
\hline$\Delta \mathrm{X}\left(\mathrm{mg} / \mathrm{cm}^{2}\right)$ & $\Delta \mathrm{E}(\mathrm{MeV})$ & $\hat{\mathrm{H}}(\mathrm{Sv} / \mathrm{hr})$ \\
\hline 0.5098 & 0.36 & 192 \\
\hline 1.3878 & 1.08 & 212 \\
\hline 1.8105 & 1.418 & 213 \\
\hline 3.4550 & 3.114 & 245 \\
\hline 3.8741 & 3.537 & 248 \\
\hline
\end{tabular}

Table (6): thickness, equivalent dose rate and energy loss for PP

\begin{tabular}{|c|c|c|}
\hline$\Delta \mathrm{X}\left(\mathrm{mg} / \mathrm{cm}^{2}\right)$ & $\Delta \mathrm{E}(\mathrm{MeV})$ & $\hat{\mathrm{H}}(\mathrm{Sv} / \mathrm{hr})$ \\
\hline 0.2162 & 0.161 & 203 \\
\hline 0.3219 & 0.24 & 203 \\
\hline 0.7491 & 0.572 & 208 \\
\hline 1.4644 & 1.089 & 202 \\
\hline 1.8053 & 1.287 & 194 \\
\hline 2.1272 & 1.705 & 218 \\
\hline
\end{tabular}

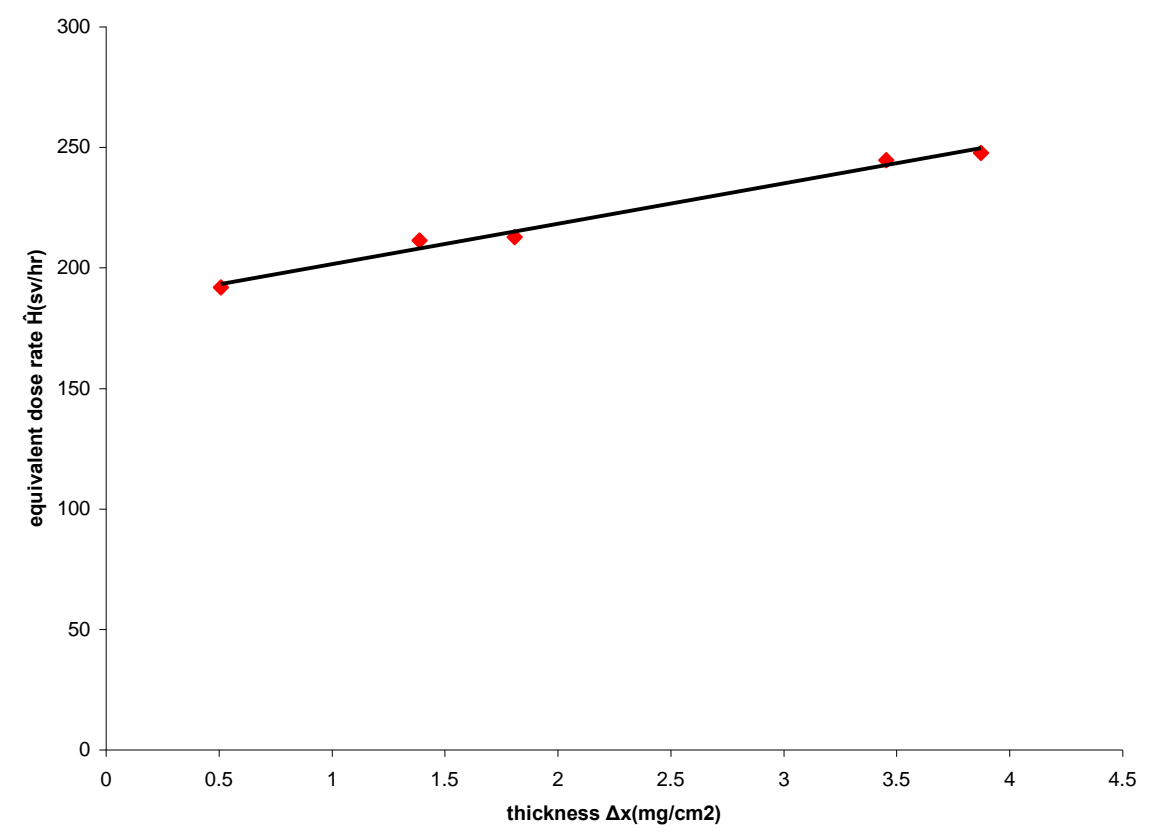

Figure ( $\left.{ }^{\natural}\right)$ : The dependence of the equivalent dose on thickness for PE 


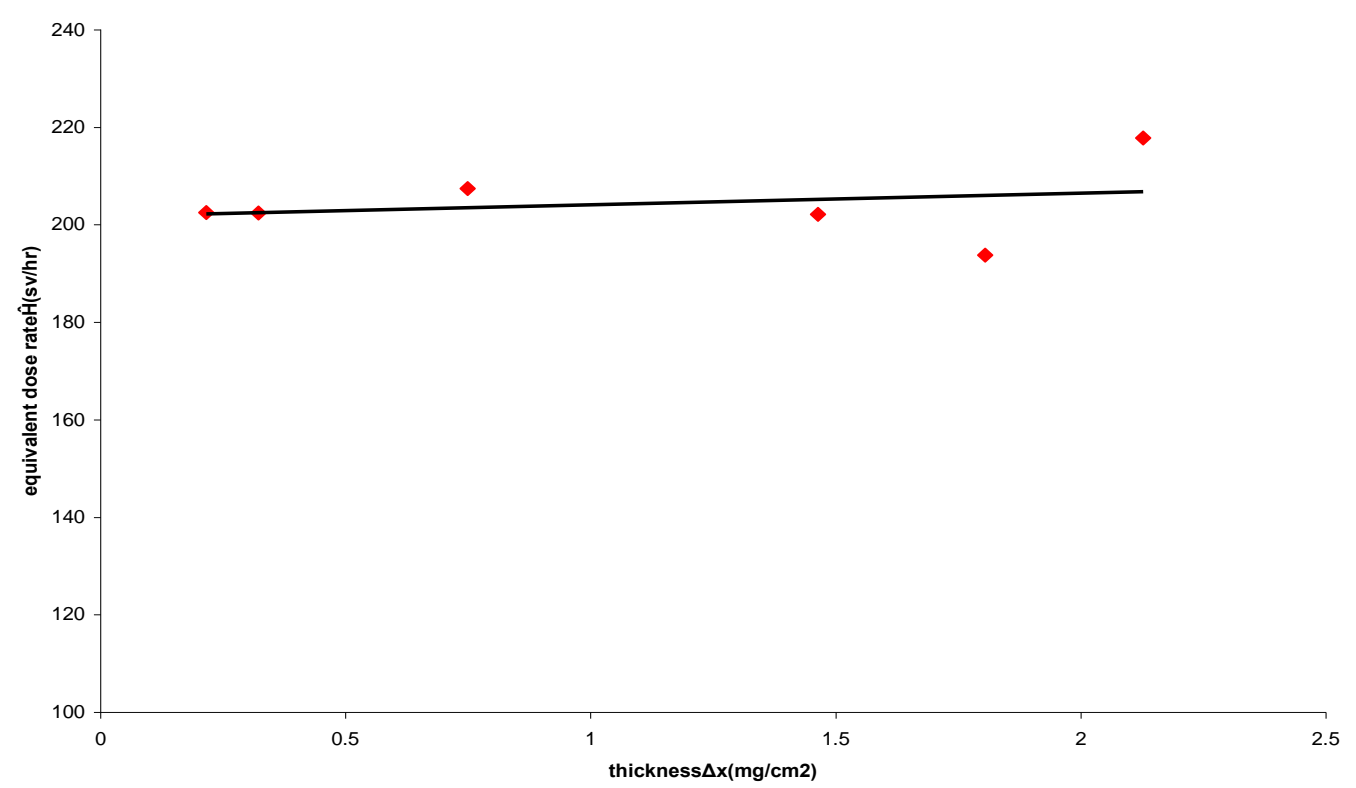

Figure ( $\vee$ ): The dependence of the equivalent dose on thickness for PP

\section{Conclusions}

1) The experimental stopping powers of $\alpha$-particles in PE is higher than that in PP. The present experimental data can be regarded to be in good agreement with the predicted values calculated by SRIM-2003.

2) Empirical formulae between stopping power and average energy, between residual range and residual energy have been obtained.

3) The equivalent dose rate increased almost linearly with thickness of PE and PP. 


\section{References}

1) Ziegler J. F. and Manoyan J. M., Nucl. Instr. and Meth. B, 35,215228 (1988).

2) Al-Ahmad K. O. and Watt D. E., J. Phys. D. Appl. Physc. 17(1984).

3) Mheemeed A. K. and Rabih L., J. Educ \& Sci Vol. 38 (1999).

4) Mheemeed A. K. and Ihsaan H., J. Educ \& Sci Vol. 42 (2000).

5) Inkret, W. C, Eisen. Y., Harvey. W. F., Koehler. A. M. and Rajo. M. R., Radiation Research 123,304-310 (1990)

6) Yu K. N., Yip C. W. Y., Nikezic D., Ho J. P. Y. and Ko V. S. Y., Applied Radiation and Isotopes, 59, 363-366 (2003).

7) Hsu J. Y., Yu Y. C., Liang J. H., Chen K. M. and Niu H., Nucl. Instr. and Meths. in Phys. Res. B 219-220, 251-255 (2004).

8) Ammi H., Mammer S., and Allab M., Nucl. Instr. and Meth. in Phys. Res. B 213, 60-64 (2004).

9) YU Y. C. , Hsu J. Y., Liang J. H. and Chen K. M., Nucl. Instr. and Meth. in Phys. Res. B 249, 47-50 (2006) .

10) Diwan P. K., Sharma V., Kumar S., Mittal V. K., Khan S. A. and Avasthi D. K., Nucl. Instr. and Meth. in phys. Res. B 258, 293-298 (2007).

11) Diwan P. K., Sharma V., Aggarwal S., Kumar S., Sharma S. K., Mittal V. K., Sannakki B., Mathad R. D., Khan S. A. and Avasthi D. K., Nucl. Instr. and Meth. in Phys. Res. B 244, 289-293 (2006).

12) YU Y. C., Hsu J. Y., Chen K. M. and Wang C. H. To appear in Nucl. Instr. and Meths. in phys. Res. B (2008).

13) Ibrahim D. T., M.Sc. Thesis. University of Baghdad (1981).

14) Gautam D. Badhwar and Francis A., Cuciontta. Radiation Research 149, 209-218 (1998).

15) Ziegler J.F. and Biersack J.P., SRIM-2003.26.http://www.srim.org./.

16) Al-Ahmad K. O., Introduction to Health Physics, University of Mosul Press. (1993).

17) Al-Ahmad K. O., J. Educ \& Sci. Vol. 19 (1994).

18) Krane, S. K., "Introductory Nuclear physics" John wiley and sons, 170-173 (1987).

19) Abdulla A. A., Al-Dargazelli S. S. and Ellias M. M, "Experimental Nuclear Physics", Higher Education Press. (1990).

20) Rabih L., M.Sc. Thesis. University of Mosul. (1997). 